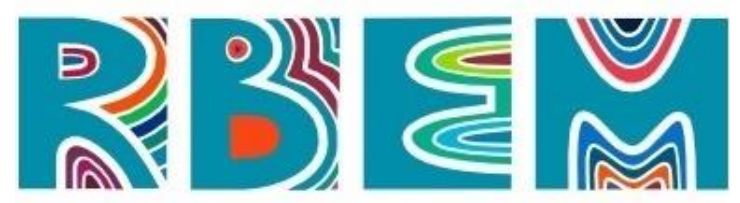

REVISTA BAIANA DE EDUCAÇÃO MATEMÁTICA

\title{
EDITORIAL
}

do1 https://doi.org/10.47207/rbem.v2i01.13318

\section{O Estágio Curricular Supervisionado em Matemática nos contextos de ensino presencial, remoto e híbrido - Dossiê Temático}

\author{
Editores Convidados: \\ FIORENTINI, Dario \\ Universidade Estadual de Campinas (UNICAMP). Pós-Doutorado. ORCID: https://orcid.org/0000-0001-5536- \\ 0781. E-mail: dariof@unicamp.br. \\ PINA NEVES, Regina da Silva \\ Universidade de Brasília (UnB). Pós-Doutorado. ORCID: https://orcid.org/0000-0002-7952-9665. \\ E-mail: reginapina@gmail.com. \\ BRAGA, Maria Dalvirene \\ Universidade de Brasília (UnB). Mestra. ORCID: https://orcid.org/0000-0003-0948-8228. \\ E-mail: dalvirenebraga@gmail.com.
}

Editor-Chefe:

SILVA, Américo Junior Nunes da

Universidade Federal de São Carlos (UFSCar). Doutor. ORCID: https://orcid.org/0000-0002-7283-0367. E-mail: ajnunes@uneb.br.

Editor-Assistente:

VIEIRA, André Ricardo Lucas

Instituto Federal de Educação, Ciência e Tecnologia do Sertão Pernambucano (IF Sertão-PE). Mestre. ORCID: https://orcid.org/0000-0002-9279-5802. E-mail: sistlin@uol.com.br.

\section{Editorial}

É com grande satisfação que disponibilizamos à comunidade científica brasileira de Educação Matemática o Dossiê Temático que tem como objeto de estudo o Estágio Curricular Supervisionado em Matemática e que foi desenvolvido em diferentes contextos de ensino presencial, remoto e híbrido, totalizando 26 trabalhos, sendo 19 Artigos e sete (7) Relatos de Experiência. Esses estudos foram produzidos por pesquisadores e pesquisadoras de instituições públicas e privadas, provenientes de todas as regiões do país.

O Estágio Curricular Supervisionado (ECS) é uma etapa importante e fundamental do processo de formação do professor. Trata-se de um momento em que o licenciando volta à prática escolar para estudá-la e compreendê-la, projetando e realizando ações que visam concretizar essa experiência como aprendiz de professor. É, portanto, uma fase rica de 


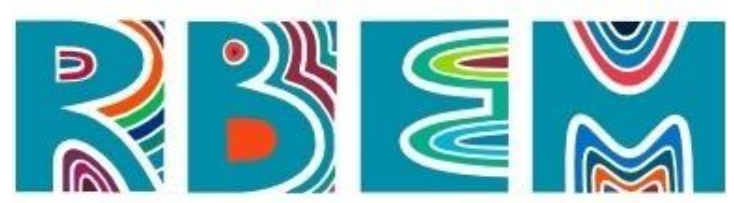

REVISTA BAIANA DE EDUCAÇÃO MATEMÁTICA

aprendizagem e desenvolvimento profissional e de constituição de sua identidade como professor de matemática.

Entretanto, nos anos de 2020 e 2021, em decorrência da pandemia provocada pelo coronavírus (Covid-19), estagiários, formadores e coordenadores de estágio da universidade e supervisores da escola básica foram desafiados a reinventar suas práticas formativas. Desse modo, foi necessário mobilizar recursos tecnológicos e negociar outras possibilidades formativas, sob uma nova organização curricular, de modo que o estágio, ainda que remoto, pudesse ser um espaço-tempo relevante de formação e aprendizagem do futuro professor de matemática, tendo a prática de ensinar e aprender matemática na escola como campo de experiência profissional e de estudo teórico-prático. Diante dessa nova realidade, os formadores tentaram responder à seguinte pergunta-chave: como contemplar no ECS, ainda que parcialmente, essa perspectiva formativa diante das restrições impostas pelas políticas sanitárias, sobretudo diante da impossibilidade da presença física dos alunos nas escolas, bem como dos estagiários em um ambiente tipicamente escolar?

Assim, várias experiências de ECS em matemática surgiram ou foram improvisadas e realizadas em todo o Brasil. Muitas dessas experiências passaram a ser sistematizadas e investigadas, seja em forma de artigos ou de relatos de experiência. Isso motivou à RBEM a abrir uma chamada pública de trabalhos relativos ao campo de Estágio Curricular em Matemática, priorizando os as experiências realizadas no período da crise sanitária, provocada pelo coronavírus. A maioria desses estudos (22 trabalhos) tomou como experiência ou contexto de estudo e investigação o estágio em Matemática, desenvolvido em situação de ensino remoto, virtual, semipresencial ou híbrido, ou seja, apenas quatro trabalhos deste Dossiê não se reportaram diretamente ao contexto da pandemia ou ao ensino remoto, mas apresentam contribuições importantes para a compreensão ou proposição de práticas possíveis de estágios nesse contexto.

Esse é o caso do artigo de Lima e Barbosa (2021), ao investigar as expectativas de futuros professores de matemática em relação ao estágio supervisionado. $\mathrm{O}$ artigo de Felcher e Ferreira (2021) apresenta e analisa as perspectivas e os desafios expressos por estagiários ao vivenciarem as experiências do ECS em matemática, bem como suas aprendizagens docentes nesse contexto. Araujo, Souza e Porto Nascimento, por sua vez, relatam uma experiência de ECS, descrevendo e narrando como foram mobilizados conceitos e procedimentos matemáticos em atividades lúdicas e desafiadoras, como jogos e uso de materiais manipuláveis, visando estimular o interesse, a curiosidade e o espírito de investigação dos alunos da escola. Por último, embora o artigo de Pires e Mendes (2021) não tenham investigado uma experiência de estágio no contexto pandêmico, o estudo documental de trabalhos sobre estágio e formação docente permitiu-lhes tecer reflexões e discussões acerca dos limites e possibilidades de alternativas metodológicas para o ensino de Matemática em ambiente de aprendizagem virtual ou de ensino remoto.

Em relação aos 22 trabalhos que tomaram como foco de estudo e reflexão as experiências de ECS de matemática no contexto pandêmico, estes nos revelam dificuldades, 


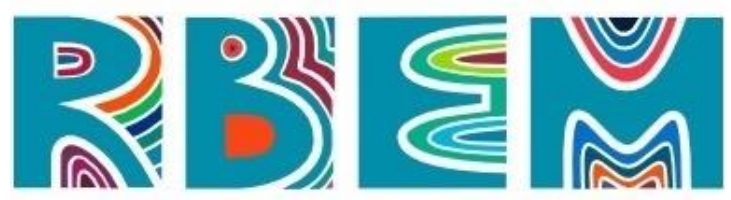

REVISTA BAIANA DE EDUCAÇÃO MATEMÁTICA

adaptações e reinvenções no fazer docente e discente, na educação básica e no ensino superior, tendo em vista os protocolos de isolamento e distanciamento social. Eles analisam e discutem ações do período de suspensão de aulas presenciais e ações adotadas para a realização do ensino remoto emergencial ou em sistemas híbridos; mostram como as instituições, os gestores e os formadores de professores revisaram documentos normativos, convênios e projetos pedagógicos e construíram práticas de ensino e de aprendizagem docente no âmbito deste componente curricular. Tudo isso em meio às preocupações de desigualdades no acesso às tecnologias, às redes de apoio ou à limitação de espaços formativos para formadores de professores, professores e futuros professores.

Desse modo, muitos dos questionamentos postos na chamada pública deste dossiê foram respondidos nos estudos, entre eles: Como esse componente curricular tem sido ofertado? Como as horas têm sido distribuídas e trabalhadas na Universidade e na Escola? Quais têm sido os desafios dos formadores de professores na interação com o futuro professor e entre estes e os professores e estudantes da educação básica? Quais têm sido as estratégias didáticas mais exitosas em contextos de aulas remotas ou híbridas? Como os aprendizados construídos por formadores de professores, professores e futuros professores, no contexto das aulas presenciais, os auxiliam no contexto de aulas remotas ou híbridas?

Nesse sentido, os estudos explicitam o cuidado dos pesquisadores em ouvir os estagiários, compreender suas percepções, seus entendimentos sobre o estágio e sobre a formação para a docência em matemática (PROENÇA; MENDES; OLIVEIRA, 2021). Eles mostram, também, a preocupação em acessar, a perspectiva do professor supervisor, entender porque eles recebem estagiários em suas salas de aula, mesmo na pandemia; o que eles esperam dessa parceria; como eles se percebem formadores de futuros professores, entre outros aspectos. Assim, os artigos relatam a ampliação do número de professores supervisores que atuam no estágio em ações de natureza colaborativa, com escola e universidade em parcerias, cada vez mais, equânimes (PINA NEVES; BRAGA; FIORENTINI, 2021).

Os estudos contribuem ao discutirem, em seus contextos, a (re)organização do Estágio Curricular Supervisionado, da Licenciatura em Matemática frente ao ensino remoto emergencial e ao ensino híbrido, abordando aspectos organizacionais, metodológicos e tecnológicos (ANDRADE; BEZERRA; CAETANO, 2021; ARAÚJO; GRILO, 2021; LIMA; SILVA, 2021). Para tanto, muitos deles assumiram como objeto de investigação as orientações curriculares e os regulamentos institucionais, revelando aspectos de sua construção e como elas impactaram na oferta da disciplina (ZAMPIERI; SOUSA; GAMA, 2021). Outros discutiram as adequações e estratégias em termos de uso de recursos tecnológicos para os momentos síncronos e assíncronos, tanto na universidade quanto na escola, além de alterações de carga horária para a realização das etapas de observação, colaboração e regência (ARAÚJO; MARIN; SOUZA JUNIOR, 2021). Dois estudos buscam descrever e analisar, comparativamente, os processos formativos relativos ao ECS presencial e ao realizado de forma remota, durante a pandemia (MIOLA; JORGE; PEREIRA, 2021; VIANA; MENDUNI-BORTOLOTI). 


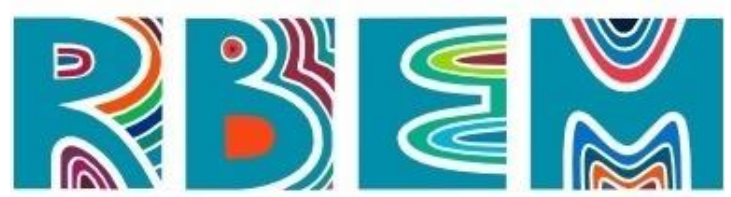

REVISTA BAIANA DE EDUCAÇÃO MATEMÁTICA

Os relatos de experiência e os artigos também nos ajudam a compreender, no âmbito de atuação dos estagiários, o ensino remoto que tem sido possível realizar nas escolas brasileiras, e os principais problemas e limitações deste modo emergencial de ensinar e aprender na escola, durante a realização do ECS (SILVA; BORELLI, 2021). Outros destacam e descrevem as aprendizagens docentes - em termos de produção e mobilização dos conhecimentos da docência em matemática - e que os estagiários conseguiram auferir neste processo de estágio emergencial e remoto (JULIO; LIMA, 2021; MARTINS; NASCIMENTO; CARVALHO, 2021; SANTOS; SILVA: CEDRO, 2021). Um terceiro estudo, nessa mesma perspectiva, descreve e discute contribuições importantes para a vivência docente de uma estagiária que realizou estágio supervisionado remoto, no ensino de álgebra para alunos do $7^{\circ}$ ano, no qual desenvolveu a sua capacidade de mobilizar referenciais teóricos para responder às demandas que surgem em sala de aula (CHAGAS; FERREIRA, 2021).

É possível observar, também, que muitos formadores, professores e estagiários de matemática vivenciam condições de trabalho desfavoráveis em função de limitações de acesso à energia elétrica, à internet, a computadores e aparelhos celulares, além de muitos não possuírem locais adequados em seus domicílios. E esta situação é agravada pelas condições ainda mais precárias dos discentes desses estagiários que frequentam a escola pública, sobretudo em bairros periféricos das grandes cidades (BURIGATO; SANTOS, 2021; SANTOS; DEODATO, 2021).

Resistindo às dificuldades, alguns estudos apresentam experiências exitosas de Estágio Remoto Emergencial, envolvendo diferentes formas de resolução de problemas, a partir de registros propostos pelos estagiários (MENDUNI-BORTOLOTI; OLIVIERA, 2021). Outra experiência relevante de ECS foi realizada visando compreender as adaptações, os desafios e as inovações necessárias ao desenvolver o estágio mediante processo de Lesson Study on-line em situação de Ensino Remoto Emergencial. Esse processo permitiu integrar colaborativamente professores orientadores e supervisores de diferentes escolas e universidades, constituindo uma rica experiência de desenvolvimento profissional, não apenas dos estagiários, mas também dos formadores participantes (PINA NEVES; BRAGA; FIORENTINI, 2021).

Outros descrevem práticas docentes em diferentes instituições desenvolvidas com o apoio de plataformas, softwares, apps e outros recursos que exemplificam a capacidade de (re)invenção e a inovação de todos os responsáveis pelo estágio. No entanto, eles também denunciam que é preciso garantir o direito à educação, à formação inicial de qualidade e às políticas públicas que ampliem as oportunidades de acesso e permanência do(a) do licenciando(a) na graduação.

A abordagem qualitativa de pesquisa se sobressai nos estudos realizados, sendo alguns desenvolvidos como estudos de caso. Mas há também estudos envolvendo pesquisa documental ou revisão sistemática. Os instrumentos mais utilizados para a construção dos dados foram os portfólios virtuais, relatórios de estágio, arquivos compartilhados em drives, 


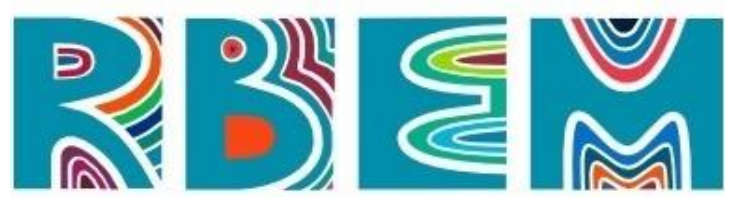

REVISTA BAIANA DE EDUCAÇÃO MATEMÁTICA

diários de bordo, escrita de narrativas, entre outros. A partir dessas escolhas, alguns pesquisadores discutem a estrutura da aula de matemática e a adoção da resolução de problemas no ensino remoto emergencial, ao mesmo tempo em que promovem que a aula de matemática seja um espaço de escrita, leitura e investigação matemática; de socialização de estratégias de resolução com respeito aos estudantes e aos seus ritmos de aprendizagem. Outros apresentam ações formativas que aproximaram os estagiários da Educação de Jovens e Adultos (EJA) e de contextos de educação não formal, entre outros (ZANON, 2021). Nessas situações, os autores destacam a necessidade de conhecer o perfil do estudante a ser atendido e seus interesses para a construção de metodologias de ensino adequadas.

Os estudos são consensuais ao revelarem que, independente da região do país, os estudantes apresentaram, inicialmente, baixo índice de presença nas aulas síncronas, baixa realização das tarefas propostas para os momentos assíncronos e, quando presentes nas aulas assíncronas, manifestavam-se pouco no chat ou por meio da fala, ficando, em sua maioria, com as câmeras fechadas. Em resposta a essa situação, os estudos expressaram a necessidade da aula de matemática promover adesão e participação entre os estudantes, o que impôs aos estagiários, professores orientadores e supervisores o desafio de planejar aulas que fossem mais inclusivas e convidativas à participação efetiva dos discentes da escola. Esse desafio pode ser observado em vários estudos que questionam o futuro da aula de matemática centrada, prioritariamente, no professor (definição, exemplo, exercício) frente ao desafio, explicitado durante o ensino remoto, de construir propostas de aulas exploratórias e investigativas, nas quais o estudante tenha mais espaço de participação, de fala, de negociação de significados.

Do mesmo modo, os pesquisadores apresentam falas convergentes quando situam o ensino remoto emergencial como propulsor, entre os professores, de discussão, interesse, curiosidade, estudo sobre recursos tecnológicos e sua utilização na aula de matemática. Assim, consideram que algo visto como negativo, repentino e difícil tornou-se, aos poucos, necessário e imprescindível para a docência em matemática e para quem se prepara para ela. Eles exemplificam, inclusive, o quanto as plataformas digitais facilitaram a gravação de aulas, a preservação de discussões e de reuniões e o quanto estes materiais digitais passaram a ser utilizados como objetos de estudo no estágio (BRAGA; PINA NEVES; MENDONÇA; OLIVEIRA, 2021).

De modo geral, os resultados desses estudos destacam que o estágio contribui para a aprendizagem docente e para a construção da identidade profissional dos futuros professores de matemática, sobretudo por oportunizar o seu desenvolvimento profissional e a qualificação de suas práticas pedagógicas. Acreditamos que o estágio, mesmo realizado em condições adversas e precárias durante a pandemia, como mostram os trabalhos deste Dossiê, representa um momento importante e fundamental do processo de formação docente, permitindo reafirmar sua escolha profissional e contribuir para a iniciação mais consistente e qualificada da carreira docente. 


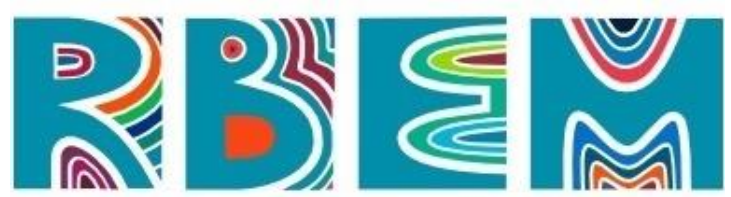

REVISTA BAIANA DE EDUCAÇÃO MATEMÁTICA

Destarte, os estudos que compõem este dossiê nos sugerem a criação de observatórios de estágio, nos quais as práticas, as condições de oferta, o desenvolvimento das intervenções letivas nas escolas, as diferentes formas de parceria e colaboração entre universidade e escola, entre universidade e secretarias municipais e estaduais de educação e entre formadores da Universidade, estagiários e supervisores da escola possam ser amplamente mapeadas, descritas, analisadas e permanente avaliadas; de modo a adaptar e transformar este componente curricular da formação inicial em alinhamento com as necessidades da escola e da sociedade, seja em contexto pandêmico, seja no contexto mutável do mundo contemporâneo atual.

Diante de tudo isso, convidamos você leitor e leitora a conhecer e refletir conosco sobre os 24 estudos que compõem este Dossiê temático e seus resultados, e, a partir deles, contribuir com novos estudos que possam ampliar este campo de conhecimento, superando as limitações ou problemas evidenciados.

\section{Referências}

ANDRADE, S. V. R.; BEZERRA, R. C.; CAETANO, R. S. Estágio Curricular Supervisionado na Pandemia da Covid-19: (Re) pensando a formação inicial do professor de Matemática. In: Revista Baiana de Educação Matemática, v. 02, n. 01, p. 01/20, e202122, jan./dez., 2021. DOI: 10.47207/rbem.v2i01.12397.

ARAUJO, A. S.; SOUZA, P. N.; PORTO NASCIMENTO, A. M. Oficinas de Matemática no Projeto Social Cata-Vento: uma prática em Educação Não Formal. In: Revista Baiana de Educação Matemática, v. 02, n. 01 p. 01-20, e202128, jan./dez., 2021. DOI: 10.47207/rbem.v2i01.12086.

ARAÚJO, H. M. C.; MARIN, D.; SOUZA JUNIOR, A. J. Estágio Supervisionado na formação de professores de Matemática, na modalidade a distância: reflexos da pandemia. In: Revista Baiana de Educação Matemática, v. 02, n. 01, p. 01-25, e202132, jan./dez., 2021.

ARAÚJO, M. L. H. S.; GRILO, J. S. P. Reconfigurando o Estágio Curricular Obrigatório em Matemática para o Contexto de Ensino Remoto Emergencial. In: Revista Baiana de Educação Matemática, v. 02, n. 01, p. 01-25, e202111, jan./dez., 2021. DOI:

10.47207/rbem.v2i01.12146.

BRAGA, M. D.; PINA NEVES, R. S.; MENDONÇA, M. P. N.; OLIVEIRA, C. F. B. O Estágio Curricular Supervisionado e o Ensino Remoto: percepções de futuros professores de matemática. In: Revista Baiana de Educação Matemática, v. 02, n. 01, p. 01-25, e202130, jan./dez., 2021. DOI: 10.47207/rbem.v2i01.12765.

BURIGATO, S. M. M. S.; SANTOS, C. M.. Condições e restrições do estágio supervisionado no ensino remoto, no curso de Matemática - Licenciatura Da UFMS. In: Revista Baiana de Educação Matemática, v. 02, n. 01, p. 01-24, e202124, jan./dez., 2021. DOI:

10.47207/rbem.v2i01.12389. 


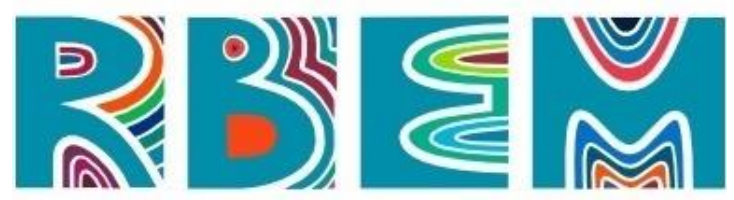

REVISTA BAIANA DE EDUCAÇÃO MATEMÁTICA

CHAGAS, I. B.; FERREIRA, A. R. C. Vivências no ensino de Álgebra no $7^{\circ}$ ano em contexto remoto a partir de uma experiência no Estágio Supervisionado. In: Revista Baiana de Educação Matemática, v. 02, n. 01, p. 01-26, e202114, jan./dez., 2021. DOI:

10.47207/rbem.v2i01.12311.

FELCHER, C. D. O.; FERREIRA, A. L. A. O estágio curricular supervisionado na compreensão de licenciados : Perspectivas, Desafios e Aprendizagens. In: Revista Baiana de Educação Matemática, v.02, n.01, p. 01-20, e202112, jan./dez., 2021. DOI:

10.47207/rbem.v2i01.12392.

JULIO, R. S.; LIMA, D. C. Produções de conhecimento a partir do estágio de forma remota no Ensino Médio em Minas Gerais. In: Revista Baiana de Educação Matemática, v. 02, n. 01, p. 01-20, e202120, jan./dez., 2021., DOI: 10.47207/rbem.v2i01.11996.

LIMA, A. C. S.; BARBOSA, P. L. Estágio Supervisionado como espaço de aprendizagem na licenciatura em Matemática. In: Revista Baiana de Educação Matemática, v. 02, n. 01, p. 01/19, e202123, jan./dez., 2021., DOI: 10.47207/rbem.v2i01.12017.

LIMA, F. J.; SILVA, R. Para além das aparências: desafios e percepções diante da oferta do Estágio Supervisionado na Licenciatura em Matemática do IFCE campus Cedro no contexto do ensino remoto. In: Revista Baiana de Educação Matemática, v. 02, n. 01, p. 01-20, e202109, jan./dez., 2021. DOI: 10.47207/rbem.v2i01.12370.

MARTINS, P. B. M.; NASCIMENTO, J. C. P.; CARVALHO, J. G. Conhecimentos e aprendizagens produzidas e mobilizadas por futuros professores em uma disciplina de Estágio Possibilidades no Contexto Pandêmico. In: Revista Baiana de Educação Matemática, v. 02, n. 01 p. 01-24, e202127, jan./dez., 2021. DOI: 10.47207/rbem.v2i01.12132.

MENDUNI-BORTOLOTI, R. D’ A.; OLIVEIRA, K. V. G. A Resolução de Problemas enquanto metodologia de ensino no Estágio Remoto Emergencial. In: Revista Baiana de Educação Matemática, v. 02, n. 01, p. 01-23, e202133, jan./dez., 2021. DOI: 10.47207/rbem.v2i01.12159.

MIOLA, A. F. S.; JORGE, N. M.; PEREIRA, P. S. Estágio Supervisionado em Matemática e a Espiral Formativa: uma experiência vivenciada em aulas presenciais e remotas. In: Revista Baiana de Educação Matemática, v. 02, n. 01, p. 01-19, e202125, jan./dez., 2021. DOI: 10.47207/rbem.v2i01.12400.

PINA NEVES, R. S.; BRAGA, M. D.; FIORENTINI, D. Estágio Curricular Supervisionado em Matemática em Processo de Lesson Study on-line: adaptações, desafios e inovações. In: Revista Baiana de Educação Matemática, v. 02, n. 01, p. 01-31, e202135, jan./dez., 2021. DOI: $10.47207 /$ rbem.v2i01.13139.

PIRES, M. A. L. M.; MENDES, I. A. Estágio Supervisionado na Formação Inicial de Professores de Matemática: limites e possibilidades. In: Revista Baiana de Educação 


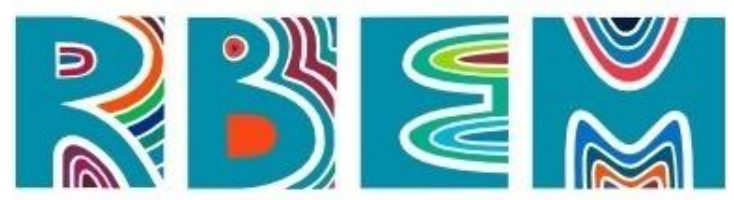

REVISTA BAIANA DE EDUCAÇÃO MATEMÁTICA

Matemática, v. 02, n. 01, p. 01-22, e202113, jan./dez., 2021. DOI: 10.47207/rbem.v2i01.12166.

PROENÇA, M. C.; MENDES, L. O. R.; OLIVEIRA, A. B. Estágio Curricular Supervisionado no Contexto do Ensino Remoto: análise da visão de futuros professores de Matemática. In: Revista Baiana de Educação Matemática, v. 02, n.1, p. 01-21, e202108, jan./dez., 2021. DOI: 10.47207/rbem.v2i01.11965.

SANTOS, M. R. DOS; DEODATO, A. A. Estágio Remoto de Matemática: o que se mostra além da tela plana? . Revista Baiana de Educação Matemática, v. 2, n. 01, p. e202129, 7 dez. 2021.

SANTOS, J.; MOREIRA, J.; DA SILVA, J. N. D. Uma Experiência de Estágio Supervisionado no Ensino Remoto: Um trabalho com a cesta básica. Revista Baiana de Educação Matemática, v. 2, n. 01, p. e202115, 7 dez. 2021.

SANTOS, I. S. G.; SILVA, J. M. B.; CEDRO, W. L. Aprendendo a ensinar Matemática no Ensino Remoto. In: Revista Baiana de Educação Matemática, v. 02, p. 01-20, e202119, jan./dez., 2021. DOI: 10.47207/rbem.v2i01.12157.

SILVA, F. M.; BORELLI, S. S.. O Estágio Supervisionado na Formação Inicial do Professor: A experiência em uma escola municipal de São Paulo e os seus desafios em Tempos Pandêmicos. In: Revista Baiana de Educação Matemática, v. 02, p. 01-19, e202117, jan./dez., 2021. DOI: 10.47207/rbem.v2i01.12320.

SOUZA, J. C. S. DE; SOARES, W. M. Estágio Supervisionado na formação inicial do docente de matemática no contexto do ensino remoto: reflexões sobre a experiência do Instituto Federal de Brasília - Campus Estrutural. Revista Baiana de Educação Matemática, v. 2, n. 01, p. e202134, 7 dez. 2021.

TAVEIRA, F. A. L.; SILVA, S. R. V. O Estágio Digital Supervisionado em um curso de Licenciatura em Matemática no interior do Estado de São Paulo: uma narrativa problematizada. In: Revista Baiana de Educação Matemática, v. 02, n. 01, p. 01-17, e202131, jan./dez., 2021. DOI: 10.47207/rbem.v2i01.12385.

VIANA, D. S. B.; MENDUNI-BORTOLOTI, R. D’A. Estágio Supervisionado contribuindo com o processo formativo de uma mestranda em estágio de docência na pandemia. In: Revista Baiana de Educação Matemática, v. 02, p. 01-22, e202118, jan./dez., 2021. DOI: 10.47207/rbem.v2i01.12165.

ZAMPIERI, M. T.; SOUSA, M. C.; GAMA, R. P. O estágio supervisionado compartilhado de matemática no contexto pandêmico: ações do movimento de uma política institucionalizada. In: Revista Baiana de Educação Matemática, v. 02, n. 01, p. 01-25, e202126, jan./dez., 2021. DOI: $10.47207 /$ rbem.v2i01.12225. 


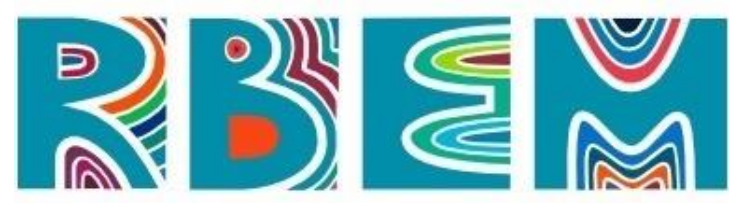

REVISTA BAIANA DE EDUCAÇÃO MATEMÁTICA

ZANON, Thiarla Xavier Dal-Cin. Entre Lives, Textos e Contextos: o Estágio Supervisionado na EJA em Tempos de Ensino Remoto. In: Revista Baiana de Educação Matemática, v. 03, n. 01, p. 01-28, e202110, jan./dez., 2021. DOI: 10.47207/rbem.v2i01.12130. 